\title{
Transfer Effects at the Syntax-Semantics Interface: The Case of Double-que Questions in Heritage Spanish
}

\author{
Alejandro Cuza and Joshua Frank \\ Purdue University
}

\begin{abstract}
This study examines the role of transfer from English in the acquisition of double-que questions in Spanish among 17 heritage speakers in the US. Results from an elicited production task, an acceptability judgment task and a preference task revealed significant difficulties in the production and acceptability of double-que questions. In contrast with interface vulnerability approaches suggesting no difficulties at the syntax-semantics interface, the participants showed a decreased level of use of double-que structures and no distinction in their acceptability of statements versus questions. However, results from the preference task showed sensitivity to double-que questions among 10 of 17 heritage speakers. It appears that only when the two structures are presented together were the heritage speakers able to perceive the semantic shift introduced by the double-que. The results suggest that transfer from the other language prevents the complete acquisition of these properties even at high levels of bilingual proficiency.
\end{abstract}

\section{Introduction}

A perennial challenge in research on bilingualism is determining the role that the other language plays in the acquisition process (e.g., Jarvis \& Pavlenko, 2008; Schwartz \& Sprouse, 1996; White, 1987; Zobl, 1980). Some researchers have argued for initial transfer effects from the first language (L1) into the second language (L2) but a full acquisition of new grammatical properties at advanced levels (Full Transfer/Full Access Hypothesis) (e.g., Schwartz \& Sprouse, 1996; White \& Genesee, 1996). Others question the ability of adult L2 learners to overcome transfer effects and to completely acquire L2 linguistic properties that are not available in their L1 (e.g., Coppieters, 1989; Hawkins \& Chan, 1997; Tsimpli \& Roussou, 1991).

More recently, researchers have examined the role of transfer from the majority language among heritage language learners (HL learners) in intense contact with English (the majority language) (e.g., Au, Knightly, Jun, Oh \& Romo, 2008; Montrul, 2002; Montrul \& Perpiñán, this issue; Rothman, 2009). Researchers argue about the extent of transfer effects and whether the difficulties exhibited by heritage speakers stem from incomplete acquisition during early childhood or if they are the reflection of a fully acquired contact variety. ${ }^{1}$ Montrul defines incomplete acquisition as the competence outcomes that arise when normal L1 development is interrupted during early childhood due to both intense contact with a second language and reduced first language input.

The objective of this study is to further examine the role of transfer from the majority language among Spanish heritage speakers in contact with English (the majority language) and the possible relation existing between acquisition difficulties and syntax-semantics interface-related 
phenomena. Specifically, we examine the extent to which Spanish HL learners have knowledge of double-que questions in Spanish (DQQ structures), a syntax-semantics interface-related structure so far unexplored and supposedly unproblematic among adult bilinguals. DQQ structures are embedded $w h$-questions introduced by the complementizer que, "that" (e.g., Plann, 1982; Rivero, 1980; Suñer, 1991). According to Suñer (1991) and others, a double complementizer is obligatory when the embedded $w h$-question is introduced by non-ask/wonder speaking verbs (e.g., to tell, to yell, to reply, to repeat). It is argued that this is common in most varieties of written and oral Spanish $^{2}$ (e.g., Demonte \& Fernández-Soriano, 2009) and usually not optional due to its semantic implications, as shown below:
a. María le dijo a Juan [adónde fueron los niños]].
(statement)
"Mary told John where the children went."
b. María le dijo a Juan [que [adónde fueron los niños]]].
(question)
"Mary asked John where the children went."

In (1a), the sentential complement is interpreted as a reported assertion or statement. In (1b), however, it is interpreted as a reported question due to the use of the complementizer que before the wh-word. Please note that in both cases the main verb in Spanish is the same (decir, "to tell") and the change in meaning is triggered by the use of the double-que. In Spanish, there is another option for embedded questions in which the verb preguntar ("to ask") is used. With preguntar, the use of the double-que is optional due to the meaning of the verb. In contrast to Spanish, English does not allow DQQ structures by virtue of the Doubly-Filled COMP Filter (e.g., Chomsky \& Lasnik, 1977), and the difference in meaning (assertion or question) is marked by the type of verb, as shown in the translations of (1a) and (1b).

Due to these parametric differences between the two languages, the acquisition task is more challenging for HL learners who are born and raised in the United States or who immigrated at a young age. The learners must expand their grammar to learn that Spanish embedded questions preceded by non-ask/wonder verbs of saying require the complementizer que before the whclause in order to distinguish interrogative questions from statements. This is also an area of the grammar not usually taught in classroom instruction. We expect that transfer from English and bilingualism effects (e.g., reduced L1 input and use) cause difficulties in the complete acquisition of this structure, evidenced by low levels of performance in the interpretation and use of doubleque questions.

To our knowledge the use of DQQ structures is common in the monolingual norm of Cuban Spanish, the dialect of our control participants. It is our understanding that it is also common in Mexican Spanish, the language variety of most of our participants' parents. However, even if the use of double-que questions is not completely categorical in the Spanish varieties examined in this study, we expect contact with English and bilingualism effects in general to cause delays in the complete specification of this interface-related structure among HL learners. This may be evidenced by low levels of acceptance and production of these DQQ structures. 
The paper is structured as follows. Section 2 examines previous research on language transfer in bilingual development and interface vulnerability approaches. Section 3 presents a syntactic analysis of double-que questions in Spanish and the hypotheses of the study. Section 4 presents a description of the participants, methodology and results. Section 5 discusses the results and provides the conclusions.

\section{Language Transfer in Bilingual Development}

\subsection{The issue of vulnerable domains}

Previous research on the role of transfer documents significant patterns of incomplete L1 acquisition among HL learners in the United Sates in several linguistic domains, including tense and aspect, mood morphology, definite articles and inflected infinitives among others (e.g., Montrul, 2004; 2009; Montrul \& Perpiñán, this issue; Polinsky, 2008; Potowski, Jegerski \& Morgan-Short, 2009; Rothman, 2007; Silva-Corvalán, 1994; 2003). Incomplete acquisition primarily affects second generation speakers born and raised in a dominant L2 context and exposed to reduced L1 contact and use during early childhood.

In most scenarios, the bilingual child becomes more dominant and comfortable in the majority language as she/he starts to develop new social networks outside the home (e.g., Lambert, 2008; Pérez-Leroux, Cuza \& Thomas, in press; Potowski, 2004). Although some HL learners do manage to maintain high levels of proficiency in both languages, especially in Spanish, researchers show that their linguistic performance is not immune to bilingualism effects. The question then is not whether bilinguals are affected by crosslinguistic influence. That is a fact of bilingualism. The question is how this process works. Are all linguistic structures equally affected? What linguistic and psycholinguistic factors tend to increase or mitigate the role of transfer from the majority language?

Along these lines of research, Sorace and colleagues postulate the Interface Hypothesis to explain L2 acquisition difficulties and L1 attrition (e.g., Belletti, Bennati \& Sorace 2007; Sorace, 2000; 2005; Sorace \& Filiaci, 2006; Tsimpli \& Sorace, 2006). L1 attrition refers to the erosion of previously acquired properties among adult immigrants in contact with a majority language (e.g., Cuza, 2010; Schmid, Köpke, Keijzer, \& Weilemar, 2004; Sorace, 2004). The authors argue that L2 developmental instability and L1 attrition primarily affect areas of the grammar where the syntax interfaces with pragmatics or discourse properties. Purely syntactic aspects or syntaxsemantics interface structures (internal interfaces) are arguably less problematic. Sorace and collaborators propose that developmental instability and L1 attrition at the interface between the syntax and other cognitive systems is more severe due to the complexity of interface-related structures. Under this assumption, Tsimpli and Sorace (2006) propose a distinction between types of interfaces and their potential degree of developmental instability. Specifically, the authors argue that it is at the syntax-pragmatic interface domain where developmental instability is more pronounced since it represents "a 'higher' level of language use and pragmatic processing” (Tsimpli \& Sorace, 2006). Syntax-semantics phenomena, on the other hand, are argued to involve "formal properties of the language system alone" and are, therefore, less likely to cause problems at advanced stages of L2 acquisition (Tsimpli \& Sorace, 2006, p. 1). The notion that it is generally more difficult to acquire grammatical domains in which the syntax 
interacts with pragmatic factors is not new. Since Liceras' (1989) study, many researchers within the generative approach have noticed this. However, this does not mean that syntax-pragmatic interface structures are permanently incomplete, or that the syntax proper is immune from transfer effects and, therefore, acquired in a straightforward fashion (e.g., Bohnacker, 2007; Ivanov, 2009).

Researchers have re-examined and debated interface vulnerability accounts in instances of child bilingual acquisition (e.g., Müller \& Hulk, 2001; Serratrice, Sorace \& Paoli, 2004), L1 attrition (e.g., Cuza, 2010; Sorace, 2000; Tsimpli, Sorace, Heycock \& Filiaci, 2004) and incomplete acquisition among HL learners (e.g., Cuza, 2009; Montrul, 2004; 2009; Montrul \& Ionin, 2010; Rothman, 2009). In the particular case of incomplete acquisition, Montrul (2004) investigated Spanish heritage speakers' knowledge of the pragmatic distribution of overt and null subject pronouns, the use of personal $-a$, and clitic-doubling. Results from an elicited production task involving twenty-four heritage speakers showed no difficulties with the syntactic realization of subjects and objects. However, participants demonstrated significant instability with the distribution of objects and with the pragmatic features of Topic and Focus that regulate overt and null subjects, as predicted by the interface vulnerability hypothesis.

More recently, Montrul \& Ionin (2010) investigated the role of transfer from English in the acquisition of the syntactic and semantic distribution of definite articles in Spanish and English by US-born Spanish HL learners. Spanish and English diverge in the semantic representation of definite articles with plural nouns, and in their representation of inalienable and alienable possession. Definite plural nouns in Spanish allow for a generic or specific interpretation according to the pragmatic context (e.g., Los niños no deben de tomar alcohol), while in English definite plural nouns are inherently specific ("The children should not drink alcohol", meaning those specific children). Spanish also uses definite articles in inalienable contexts as in Pedro levantó la mano ("Peter raised his hand"). Results from an acceptability judgment task, a truth value judgment task and a picture-sentence-task administered to twenty-three Spanish heritage speakers demonstrated significant transfer effects with the interpretation of definite articles with a generic interpretation. This is a property that is unavailable in English. However, the participants showed no problems with the use of definite articles in inalienable possession contexts. Montrul \& Ionin (2010) concluded that, for heritage speakers, syntax-semantics interface phenomena are as affected by transfer as syntax-discourse properties, confirming previous research (e.g., Montrul, 2002; 2009; Silva-Corvalán, 2003).

Other researchers have also found evidence against interface vulnerability approaches in adult L2 acquisition and child bilingual development (e.g., Bohnacker, 2007; Donaldson, 2008; Ivanov, 2009; Montrul \& Rodriguez-Louro, 2006; Rothman, 2008). For example, Rothman (2008) examined the L2 knowledge of the pragmatic distribution of null and overt subject pronouns in Spanish L2 among fifty-one intermediate and advanced English-speaking L2 learners. Results from two interpretation tasks and a translation task showed difficulties among intermediate learners in their knowledge of the pragmatic conditions that regulate the distribution of null and overt subject pronouns. However, in contrast with Sorace's proposal, Rothman found native-like performance among the advanced learners. He, therefore, concluded that although syntaxpragmatic interface phenomena are difficult to acquire, they are not destined for fossilization. 
Similar results with L2 learners were found by Ivanov (2009) while examining the L2 acquisition of Bulgarian topicality-marking clitic doubling among nineteen advanced and intermediate English-speaking L2 learners of Bulgarian. Ivanov used a context sentence evaluation task to test the L2 learners' knowledge of dative and accusative clitics in focus and topic contexts. Results showed target-like acquisition of the pragmatic constraints on clitic doubling in Bulgarian in both topic and focus conditions. In contrast with the Interface Hypothesis, advanced L2 learners showed strong preference for dative and accusative clitic doubling, which was similar to the evaluations provided by the monolingual speakers. Intermediate learners, in contrast, showed strong preference for infelicitous non-clitic use in topic conditions and patterns of convergence with English word order (SVO) with accusative and dative topic conditions. Ivanov concluded that interface structures might be problematic at intermediate stages, but they are completely acquired and target-like at advanced levels, which is contrary to the predictions of the Interface Hypothesis.

More recently, Pérez-Leroux et al. (in press) investigated the knowledge that English-Spanish bilingual children have of clitic placement in reconstruction contexts (clitic climbing) and potential syntactic priming effects. Unlike English, in which object pronouns must appear in postverbal position, in Spanish the pronominal complement of a nonfinite verb can optionally appear in either a preverbal (proclisis) (e.g., María lo quiso ver "Mary wanted to see him") or post-verbal (enclisis) position (e.g., María quiso verlo, "Mary wanted to see him). This optional word order is independent of pragmatic or discourse factors, and monolingual speakers often prefer the preverbal option (e.g., Eisenchlas, 2003). Results from an elicited imitation task testing the vulnerability of these structures to cross-language influence in twenty-three bilingual children showed a marked bias towards forward repositioning contexts (enclisis), in contrast with the preferred monolingual norm (proclisis). The authors concluded that transfer is not limited to the syntax-pragmatics/discourse interface but also affects narrow syntax proper as a logical consequence of cross-language lexical activation and typological congruence (e.g., Loebel \& Bock, 2003).

In summary, interface vulnerability approaches argue that language transfer and developmental instability mostly affect structures related to the syntax-pragmatics interface. In this view, it is argued that syntax proper and syntax-semantics interface-related structures are less impervious to transfer and remain unproblematic (e.g., Sorace, 2005; Tsimpli et al., 2004; Tsimpli \& Sorace, 2006). However, some researchers have provided evidence against interface vulnerability, suggesting that there is no direct correlation between acquisition difficulties and interface phenomena (e.g., Bohnacker, 2007; Ivanov, 2009; Montrul \& Ionin, 2010; Pérez-Leroux et. al. in press; Rothman, 2008). The present study adds to this discussion in that little research has been done on the syntax-semantics interface within the heritage language population. We examine whether adult bilinguals, specifically Spanish HL learners, are able to acquire double-que questions in Spanish. These structures are syntax-semantics interface-related, not available in the learners' majority language (English) and not taught in language classrooms.

If syntax-semantics interface phenomena are impervious to transfer effects and less likely to undergo acquisition difficulties, one would expect Spanish HL learners to have little difficulty 
with the production and interpretation of DQQ structures. However, it is also possible that these structures might be vulnerable to acquisition difficulties. Specifically, we hypothesize that heritage language learners will show low levels of production and target interpretation of doubleque questions due to transfer from English (a single complementizer structure) and reduced input and use of their minority language. We expect heritage speakers to show difficulties in this domain as a logical consequence of cross-language interaction. This will occur regardless of the fact that this structure is a syntax-semantics interface-related property. It is possible, though, that highly proficient learners will be able to overcome transfer effects and show target like behavior in the minority language (e.g., Schwartz \& Sprouse, 1996).

\section{The Syntax and Semantics of the Spanish Double-que}

3.1. The semantic role of the complementizer 'que'

As mentioned earlier, Suñer and many others have argued that embedded wh-questions in Spanish introduced by non-ask/wonder verbs of saying must have the complementizer que before the wh-word (e.g., Plann, 1982; Rivero, 1980; Suñer, 1991, 1993). The use of a double-que is arguably not optional due to its semantic role. Ask/wonder verbs, such as preguntar "to ask", always select for a question so the use of the double-que construction is optional. Plann (1982) observes that in Spanish the DQQ structure allows certain non-ask/wonder verbs of communication (e.g., decir "to tell", gritar "to yell", contestar "to reply", repetir "to repeat") to introduce true indirect questions. In English, an indirect question can only be a complement of an ask/wonder verb of communication (e.g., to ask, to wonder), as shown below:

(2) Susana le dijo a Diego que adónde fueron ellos

(indirect question)

Susan him said to Diego that where went they

"Susan asked Diego where they went"

In (2), Susan asked Diego where they went because she did not know. Susan is searching for an answer, not reporting what is known. There is a gap of knowledge here, which is characteristic of all true indirect questions. Another characteristic of indirect questions is that they can be paraphrased as a direct question, as in (3) below:

$$
\begin{aligned}
& \text { Susana le dijo a Diego: "¿Adónde fueron ellos?" (direct question) } \\
& \text { Susan him said to Diego: "Where went they" } \\
& \text { "Susan asked Diego: Where did they go?" }
\end{aligned}
$$

Because English does not allow the DQQ construction, all non-ask/wonder verbs of communication followed by an indirect question must be interpreted as semi questions or assertions. Even Spanish sentences that lack the DQQ structure will be interpreted as a semi question. This is represented in (4) below: 
Susan him said to Diego where went they

"Susan told Diego where they went"

Semantically, these are not questions at all. That is, Susan told Diego where they went because she knew. In this example, unlike in (2), Susan was reporting what is known, not searching for an answer. Therefore, there is no gap of knowledge. Moreover, it is impossible to paraphrase (4) as a direct question. To say Susan tells Diego: "Where they went" would be odd. A possible example is Susan tells Diego: "They went to the market." A gap of knowledge and the potential for a direct question paraphrase distinguish a semi question from an indirect question in Spanish and English. When introduced by a non-ask wonder verb (e.g., decir "to tell", gritar "to yell", contestar "to reply", repetir "to repeat"), a further distinction must be made between Spanish and English indirect questions. In Spanish, the complementizer que must immediately precede the embedded question.

\subsection{Syntactic Analysis}

According to Suñer (1991, 1993), the structure of indirect questions differs in English and Spanish. In English, the structure is simpler because English differentiates embedded statements from interrogatives through verb choice (semantics). Notice that in English the verb 'to ask' is used for the embedded question (example 2), while the verb 'to tell' is used for the assertion (example 4). Spanish, on the other hand, differentiates between these two embedded phrases by altering the structure of the indirect question and leaves the verb unchanged.

For Spanish indirect questions, altering the structure means inserting the complementizer que. As mentioned earlier, this is arguably a mandatory insertion that triggers the semantic distinction between embedded questions and statements. In order to account for what is now a more complex clause, Suñer (1991) proposes a two-phrase structure. A contrast in the complexity of the indirect question of both Spanish and English is represented in (5) below:

\section{Susana le dice a Diego [1 que [2adónde fueron (ellos)]]}

"Susan asks Diego [1where they went]]"

By positing that que belongs to a second phrase, Suñer is able to account for the que + wh word order. Moreover, Suñer argues that this two-phrase structure is applicable to all dialects of Spanish.

Building on the syntactic and semantic differences between English and Spanish regarding the use of double-que questions as well as the assumption of transfer from the majority language, we expect Spanish heritage speakers to show difficulties with the interpretation and use of the double-que constructions in interrogative questions introduced by verbs of saying. Specifically, we expect them to reject DQQ structures at higher levels than monolingual speakers and to show a bias toward the English option that does not include a double complementizer. 


\section{The Study}

\subsection{Participants}

A total of thirty-two $(n=32)$ participants took part in the study, seventeen HL learners and fifteen control participants. The participants first signed a consent form and completed a language history questionnaire. The questionnaire included two sections. Section one elicited information about the sociolinguistic background of the participants, including place of birth, languages spoken during childhood, parents' L1, language of primary instruction and patterns of language use. Participants were also asked to select which language they felt more comfortable using. Section two included a language proficiency self-assessment in English and Spanish for each of the four language skills (reading, writing, comprehension and speaking). The scale ranged from limited (1) to native-like (4). In addition to a self-assessment, a proficiency test was used.

The heritage speakers' group consisted of seventeen $(n=17)$ university-educated Spanish heritage speakers. Sixteen were born and raised in the United States and one was born in Puerto Rico. Most of the heritage speakers (82\%) were students at a large research university in the Midwest. The mean age at time of testing was 24 years old. There were eleven females and six males. In $71 \%$ of the cases, both parents were native speakers of Spanish. Most of the participants' parents were from Mexico. To determine the patterns of language use, participants were asked to indicate their language use at home, school, work, and social situations following a 7-point scale ranging from 'English only' to 'Spanish only' (adapted from Pérez-Leroux et. al., in press). 41\% of the participants reported that they use English and Spanish equally at home, $12 \%$ mostly English, and another $12 \%$ reported using mostly Spanish. At school, $47 \%$ of the participants reported speaking mostly English, while 47\% reported using only English. 59\% of the participants reported using mostly English at work, and $24 \%$ only English. In social situations, $65 \%$ indicated that they use mostly English, and 24\% used both Spanish and English equally. For the majority of the participants, English was the language of primary instruction in primary school (88\%), high school (94\%) and university (88\%). When asked which language they felt more comfortable using, most participants indicated English (65\%). All of the participants except one had visited Spanish-speaking countries in the past, but only five (29\%) reported visiting them frequently.

To evaluate the heritage speakers' level of proficiency in Spanish and English, the participants first completed a self-assessment of their language proficiency skills. Their mean self-assessment in Spanish across the four language skills was 2.7/4 (adequate) and in English it was almost native-like 3.7/4. The participants also completed a written proficiency test in Spanish and an oral narrative of Little Red Riding Hood in both languages (not reported here). The proficiency test consisted of a cloze passage (with three multiple-choice response options for each blank) from a version of the Diploma de Español como Lengua Extranjera (DELE) and a multiple choice vocabulary section from an MLA placement test. The maximum possible score on the proficiency test was 50. The same test was used in Montrul, Foote \& Perpiñán (2008). Following previous research (e.g., Montrul \& Bowles, 2010; Montrul \& Slabakova, 2003), scores between 40 to 50 points were considered as 'advanced' proficiency level, scores between 30 to 39 points were considered as 'intermediate' proficiency, and scores between 0 to 29 points were considered as "low" proficiency. Seven of the heritage speakers $(41 \%)$ fell into the advanced range (range 41-49), eight (47\%) fell into the intermediate range (range 31-38), and two 
participants (12\%) fell into the low range (28 points each). Near-native proficiency in English was assumed based on the sociolinguistic and linguistic background of the heritage speakers (born and raised in the US except one participant, schooling in English, patterns of language use, most comfortable language, self assessment).

The control group consisted of fifteen $(n=15)$ native speakers of Spanish who were raised in a monolingual environment. Fourteen of the participants were from Cuba, and one was from Colombia. The participants from Cuba had never visited nor lived in an English-speaking country. The participant from Colombia has lived in the US for one year. There were six females and nine males with a mean age at time of testing of 29 years old. Nine of the participants (60\%) were students, and the remaining participants included a doctor, an accountant and office personnel. All of the participants except two were university-educated or currently attending university. Most of the participants have taken basic English courses in high school and university, but they did not consider themselves to be bilingual speakers. Just as in the case of the heritage speakers, the control participants completed a linguistic questionnaire and a language self-assessment. Their mean self-assessment in Spanish was 4/4 (native-like) and in English it was 1.4/4 (limited). The participants also completed the DELE test and the oral narrative in Spanish of Little Red Riding Hood. The mean score per group on the DELE test was 43 points.

An independent-sample t-test was conducted to measure the obtained differences between the heritage speakers and the control participants on the DELE proficiency test. The results showed significant differences between the two groups to the advantage of the monolingual speakers $(t(29)=-3.431, p=<.002)$. The control group significantly outperformed the heritage speakers.

\subsection{Methods}

Data elicitation included a sentence completion task, an acceptability judgment task (AJT) and a preference task. The sentence completion task was presented first, followed by the AJT and the preference task. All tasks were conducted in Spanish, although sometimes instructions had to be given in English for some of the HL learners. The participants completed all tasks in one individual session in either the researcher's office or the participants' home.

The sentence completion task was administered orally using Microsoft PowerPoint. The goal of this task was to investigate whether HL learners were able to produce DQQ structures in contexts where monolingual speakers normally would. The task consisted of twenty-three tokens (twelve test items and eleven distracters). The test items targeted the use of DQQ structures with the verbs of saying decir ("to tell") and gritar ("to yell") (six items per verb). The wh-words used were cuándo ("when"), quién ("who"), adónde ("where"), and dónde ("where"). After conducting a pilot study, it was found that the use of double-que questions with the wh-word qué (Juan le dijo a María que qué compró, "John asked Mary what she bought") was not preferred among native speakers. Thus, it was excluded from the materials. The participants were instructed to (1) read and listen to a preamble followed by a matrix $w h$-question and (2) complete the sentence that followed based on the information provided in the preamble. The beginning of the sentence served as prompt to elicit the DQQ structure, as shown below:

Rosa le contó a Juan adónde fue de compras y Juan le dijo: ¿Cuándo fuiste? 
Juan le dijo a Rosa ...........................

"Rose told John where she went shopping, and John asked her: When did you go?

"John asked Rose ..........................."

Expected answer: ...que cuándo fue de compras (“...when did she go shopping)

(7) María le dijo a su madre cuándo terminó la fiesta de anoche y su madre muy molesta

le gritó: ¿Dónde fue la fiesta esta vez?

La madre le gritó a María

"Mary told her mother when the party finished last night and her mother very angry screamed at her: Where was the party this time?

"The mother screamed at Mary .............................."

Expected answer: ....que dónde fue la fiesta esta vez (“... where was the party this time”)

The preambles and the prompts were read to each participant individually by the interviewer. This was done to ensure a more natural administration of the task and so that the preambles or the prompts could be repeated more easily if necessary. A continuation rise was used while formulating the prompt. The responses were recorded with a digital tape recorder.

The acceptability judgment task (AJT) was a paper and pencil task. The goal of this task was to examine the knowledge that HL learners have of the interpretation of DQQ structures in obligatory contexts. Participants were presented with thirty-five tokens (eighteen test items and seventeen distracters) counterbalanced across participants. We tested three types of verbs of saying: decir ("to tell"), gritar ("to yell") and contestar ("to answer"). Since the verb preguntar ("to ask") allows for indirect questions with or without que (e.g., Suñer, 1991), it was excluded from the materials. We did not test other verbs of saying (e.g., murmurar, "to murmur") due to their low use in day-to-day speech among native speakers and particularly in embedded questions. The participants were instructed to (1) read the preamble, (2) read the sentence that followed, and (3) indicate if the sentence was odd, slightly odd, I don't know, more or less fine or fine. In case the participants found the sentence to be odd or slightly odd, they were asked to specify what was wrong with the sentence, as shown below:

(8) Diego le contó a Fernando con quién salió anoche y Fernando le dijo: ¿Adónde fueron?

"Diego told Fernando with whom he went out last night and Fernando asked him: Where did you go?" 
a) Fernando le dijo a Diego que adónde fueron.

"Fernando asked Diego where they went."

1 (odd) 2 (slightly odd) 3 (I don't know) 4 (more or less fine) 5 (fine)

Razón:

b) Fernando le dijo a Diego adónde fueron.

"Fernando told Diego where they went."

1 (odd) 2 (slightly odd) $\quad 3$ (I don't know) 4 (more or less fine) 5 (fine)

Razón:__no use of que"

In (8a), the expected answer was 4 or 5 . In (8b), the expected answer was 1 or 2 due to the lack of the double-que. In this task, "odd" and "slightly odd" responses were assigned a score of 1 and 2 respectively and "more or less fine" or "fine" responses were assigned a score of 4 and 5 respectively. An "I don't know" response was given a score of 3.

The preference task (e.g., Geeslin \& Guijarro-Fuentes, 2006; Montrul, 1998) was also a paper and pencil task. The objective of this task was to complement the AJT by examining the interpretation of a double-que in indirect questions introduced by verbs of saying. The task consisted of thirty-five tokens (eighteen test items and seventeen distracters) counterbalanced across participants. The participants were asked to (1) read the preamble and (2) choose one of the two sentences provided based on the italicized preamble. An example is shown in (9) below:

(9) Sandra le contó a José cuánto pagó por el carro y José le dijo: ¿A quién le pagaste tanto dinero?

"Sandra told John how much she paid for the car and John asked her: To whom did you pay so much money?"

(a)

Juan le dijo a Sandra a quién le pagó tanto dinero. "John told Sandra to whom she paid so much Money"

_. Juan le dijo a Sandra que a quién le pagó tanto dinero.

"John asked Sandra who she paid so much money.

In (9), the expected answer was (9b). If the participant chose the sentence with the doubleque construction, a score of 1 point was awarded. If the participants chose the sentence without the que, a score of 0 was awarded. 


\subsection{Results}

\subsubsection{Sentence Completion Task}

Recall that the objective of this task was to examine the use of DQQ structures in Spanish by monolingual and heritage speakers. Each response was scored as 0 for no use of double-que and 1 for the use of the double-que in an indirect question scenario. There were a total of 12 indirect question scenarios where the use of the double-que was expected. To obtain the proportion of double-que use, we added the total number of double-ques elicited by the total number of true indirect questions per participant and then pooled by group. The criterion that identified a true indirect question, as opposed to a direct quote, was the use of third person in the subordinate clause. If the third person was not used, the item was discarded from the total 12. Moreover, instances of double-que with the verb preguntar were also discarded from the analysis. We were interested in examining only the production of que introduced by non-ask/wonder verbs of saying. As expected, the heritage speakers showed low levels of production of DQQ structures (24\%) when compared with the monolingual speakers $(63 \%)$. These results are represented in Figure 1:

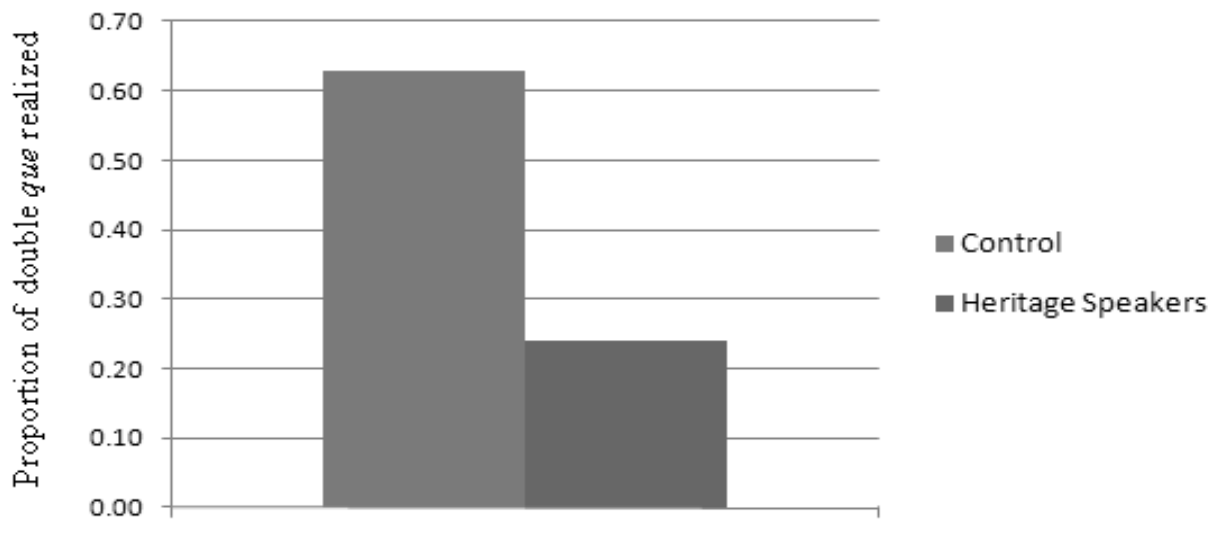

Figure 1. Sentence Completion Task. Proportion of double-que questions realized.

Since the results of the use of the double-que in indirect questions were contingent on the nonuse of the double-que ( 1 or 0 respectively), the proportions of double-que structures realized were transformed to arcsine values before performing the parametrical tests. The transformed scores were then submitted to a univariate ANOVA analysis with use of que as the dependent variable and group as the independent factor. Results showed significant differences between the two groups $(\mathrm{F}(1,30)=7.42, p<.01)$. The control group outperformed the heritage speakers significantly, confirming our expectations.

As represented in Figure 1, the control group performed at a 63\% range. Two control participants did not produce any DQQ structures, and four showed very low levels of production. These speakers produced indirect questions without the double-que, which indicates a certain level of optionality in the use of DQQ structures in the pre-contact variety in contrast with theoretical 
generalizations. In order to examine how each participant behaved within his group, we conducted an individual analysis.

\section{Individual Results}

Individual results also showed low levels of double-que realization among the two bilingual groups. To conduct this analysis, high level of production meant that the participant produced the double-que in more than $50 \%$ of the indirect questions realized. Those who produced less than $50 \%$ were considered as low level behavior participants, and those with zero production were considered as null behavior participants. Within the heritage speakers group, only 4/17 participants demonstrated a high level of use, $3 / 17$ showed a low level of use and 10/17 showed null use. In contrast, 10/15 of the control participants showed a high level of use, 3/15 demonstrated low use and only $2 / 15$ showed null behavior. These results are represented in Table 1 below:

\section{Table 1}

Sentence Completion Task: Individual Results within Group per Use of Double-que Constructions

\begin{tabular}{lccl}
\hline Group & High & Low & Null \\
\hline Heritage Speakers & $4 / 17$ & $3 / 17$ & $10 / 17$ \\
& $(23 \%)$ & $(18 \%)$ & $(59 \%)$ \\
\hline Control & $10 / 15$ & $3 / 15$ & $2 / 15$ \\
& $(67 \%)$ & $(20 \%)$ & $(13 \%)$ \\
\hline
\end{tabular}

As shown in Table 1, the heritage speakers and the control participants showed considerable differences in the level of use of double-que constructions, confirming what was expected. Most of the heritage speakers (59\%) did not use the double-que in their oral production, compared to only $13 \%$ of the control participants. A look at the proficiency level of the heritage speakers indicates no correlation between their proficiency in Spanish and performance level. Out of the seven advanced learners, three showed a high level of production, three showed null use and one show low production. One out of the eight intermediate learners showed a high level of and two showed a very low level of production. The rest of intermediate learners and the two beginners showed null use.

These results suggest incomplete acquisition of these structures among the heritage speakers. Since all but one of the participants were heritage speakers born and raised in the United States, and specifically in the American Midwest, this is not a case of L1 attrition of previously acquired properties (e.g., Silva-Corvalán, 2003; Sorace, 2004). As mentioned in the introduction, HL learners undergo, for the most part, incomplete acquisition of their native language due to limited exposure to it and intense contact with English. However, this is by no means generalized across the board, and individual differences exist, as shown by the target like behavior of four of the 
heritage speakers. Spanish heritage speakers in the US are a very heterogeneous group in terms of not only their linguistic background but also their cultural history in general (type of immigrant community, family economic status, educational opportunities). This leads to individual differences which might favor or restrain the acquisition process. However, it is clear that these structures are not easily acquired for the vast majority of the HL learners.

Interestingly, the data also showed some variability in the use of double-que among the monolingual Spanish speakers. This indicates that the use of a double-que in indirect questions introduced by verbs of saying is not categorical in the pre-contact monolingual norm of Cuban Spanish. ${ }^{4}$ These results confirm previous research on language contact among Caribbean Spanish speakers in the United States, which documents non-generalization of some linguistic rules in the pre-contact variety (e.g., Lapidus \& Otheguy, 2005). For the heritage speakers, the presence of such variability is an added burden in their acquisition task. If this variability extends to other varieties of Spanish, they may be exposed to this type of optionality and linguistic "noise" from the immigrant community.

\subsubsection{Acceptability Judgment Task}

This task tested the knowledge that heritage speakers have of the interpretation of DQQ structures. As in the oral completion task, the heritage speakers showed much lower results than their monolingual peers while judging indirect questions without que. However, both groups showed no difficulties in their judgments of indirect questions with que. In this case, both groups behaved similarly. These results are shown in Figure 2 below:

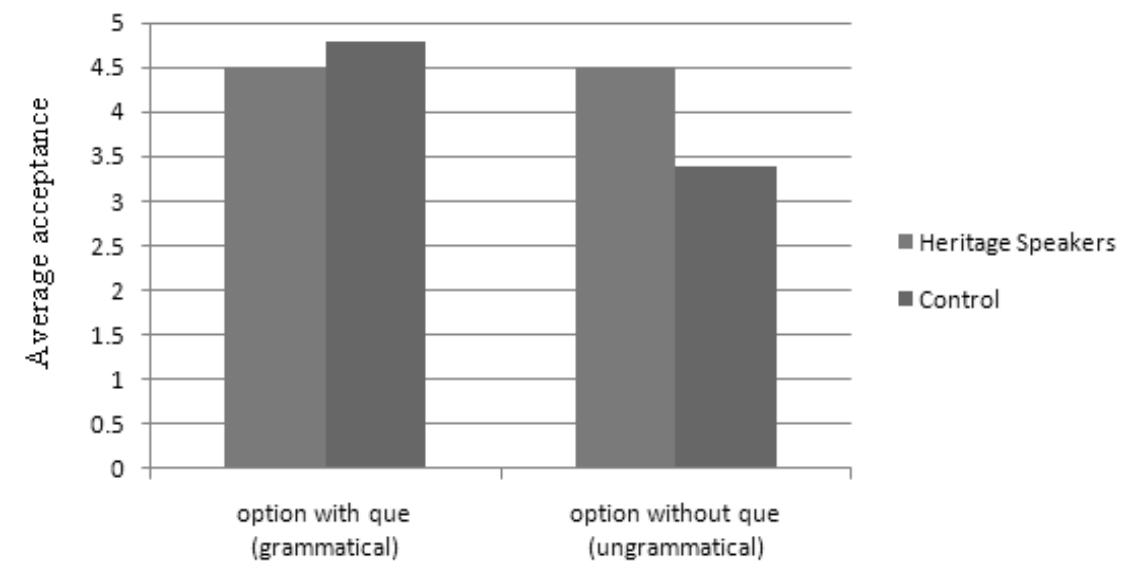

Figure 2. Acceptability Judgment Task. Mean scores for the acceptability of the option with que and without que per group.

The sentences with que were expected to show high level of acceptance since it was predicated that they would be judged as 'fine' or 'more less fine' in both the context in which they appeared and in isolation. It was expected that the sentences without que, on the other hand, would be rejected. Although they were fine in isolation (as a statement), they were odd as indirect questions in the context in which they appeared. 
Results for the average scores were submitted to a multivariate ANOVA analysis with 'option with que' and 'option without que' as the dependent variables and 'group' as the independent factor. Results showed significant differences between the two groups with the 'option without que' condition (odd) $(\mathrm{F}(1,30)=9.043, p<.005)$. The control group significantly outperformed the heritage speakers, as expected. As represented in Figure 2, the heritage speakers judged both conditions almost equally. These results appear to indicate that the heritage speakers may not have developed sensitivity to the difference in meaning implied by the lack of a double complementizer with verbs of saying. Results from the 'option with que' condition (fine) showed no significant differences between the two groups $(\mathrm{F}(1,30)=1.232, p=.276)$. Both groups showed ceiling performance in this condition.

\section{Individual Analysis}

An individual analysis conducted within groups also showed significant differences among the two groups with the 'option without que' condition, confirming the group results. For this analysis, the following criteria were followed. Six or more accepted responses ("fine" or "more less fine") out of nine (6/9) established that the participant failed to recognize the lack of the double-que, and consequent change of semantic value (accepted speakers). Five out of nine (5/9) accepted answers represented the cut-off point for unsure speakers, and four or fewer accepted responses out of nine (4/9) represented the cut-off point for rejected speakers. Table 2 displays these results:

Table 2

Acceptability Judgment Task: Individual Results within Group per No Use of Double-que Constructions

\begin{tabular}{lccc}
\hline Group & Acceptance & Unsure & Rejection \\
\hline Heritage Speakers & $16 / 17(95 \%)$ & $0 / 17(0 \%)$ & $1 / 17(5 \%)$ \\
\hline Control & $7 / 15(47 \%)$ & $3 / 15(20 \%)$ & $5 / 15(33 \%)$ \\
\hline
\end{tabular}

Ninety-five percent of the heritage speakers accepted most of the sentences without the double que construction ("ungrammatical" option) in contrast with $47 \%$ of the monolingual speakers, confirming what was expected. The heritage speakers were much less categorical than the control participants and accepted most of the sentences, except one participant who rejected all of the ungrammatical items (HSB7). The rest of heritage speakers $(n=16)$ did not differentiate between the interpretation of sentences without que and those with que with an average mean of 3.8 to 5 for both sentence types. There was no correlation between the level of proficiency and the acceptance of ungrammatical or grammatical items. Even the most advanced heritage speakers accepted both types of structures at high levels. It is possible that most of the heritage speakers in this task treated both types of constructions in free variation. Since double-que is in free variation (optional) in indirect questions introduced by the verb preguntar (to ask), it is 
possible that heritage speakers have overgeneralized this rule to verbs of saying. Therefore, they may interpret the lack of double-que as another equally possible option in Spanish and fail to recognize the change in meaning. The rejected behavior participant (HSB8) was one of the four participants who showed high levels of double-que use in the production task. The other three participants who showed high production of DQQ structures in the production task (HSA2; HSB6, HSB9) also showed a high level of acceptance of the ungrammatical items (means, 4.6, 4.4 and 4.9 out of 5 , respectively). Some monolingual speakers accepted indirect questions without the que, which shows a certain level of variability in the pre-contact variety. That is, the use of double-que questions in the monolingual norm of Cuban Spanish is not as categorical as expected. However, in contrast with the heritage speakers, most of the control participants did differentiate both sentence types, which indicates a change in the bilingual grammar.

\subsubsection{Preference Task}

To complement the results of the AJT, we also conducted a forced-choice preference task. The goal of this task was to examine the preference that heritage speakers and control participants had regarding the use of double-que questions. As explained earlier, in this task participants were presented with two sentences (one with que and another one without que), and they were asked to choose which of the two they preferred according to the preamble. There were no third or fourth options for accepting both or none. This was done to ensure that the participants made a straightforward decision as to which option they preferred according to the context. A preference for the option without que condition received a score of 0 , and a preference for the option with que condition was awarded a score of 1 . There were a total of 18 sentence pairs plus distracters.

As in the case of the AJT, the heritage speakers showed a tendency to accept both types of structures at the group level. In contrast, the control participants showed higher levels of acceptance of the option with que and consequent lower levels of preference for the option without que. These results are represented in Figure 3 below:

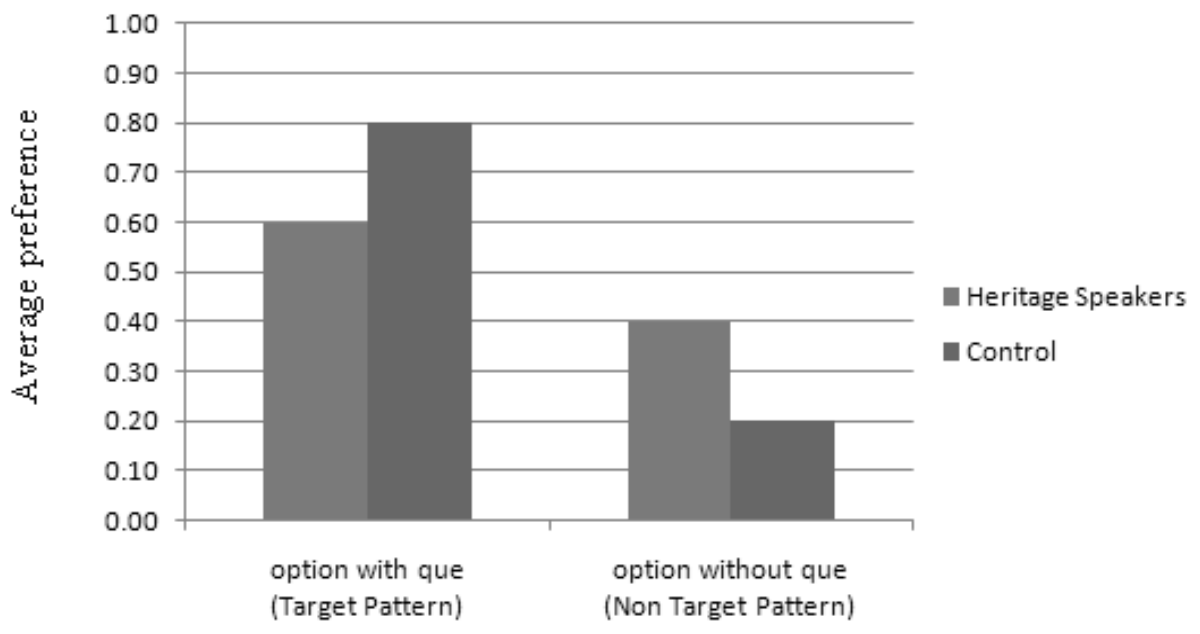

Figure 3. Preference Task. Mean scores of preference for the option with que and the option without que per group 
As in the case of the oral production task, the average scores were transformed to arcsine values before conducting the parametrical tests. The transformed scores were then submitted to a multivariate ANOVA analysis with 'option with que' and 'option without que' as the dependent variables and 'group' as the independent factor. As expected, results for the 'option without que' condition showed significant differences per group to the advantage of the control participants $(\mathrm{F}(1,30)=6.207, p<.018)$. The results also showed significant differences with the 'option with $q u e$ ' condition $(\mathrm{F}(1,30)=6.059, p<.020)$. Thus, our expectations were confirmed by the results.

\section{Individual Analysis}

In order to examine whether the heritage speakers and the control participants behaved differently at the individual level on the 'option with que' condition (grammatical condition), we conducted an individual analysis using the following criteria. Participants who chose the option with que 10 times or more out of $18(10+/ 18)$ were considered as 'preference' speakers (target behavior); participants who chose the option with que 9 times out of 18 were considered as 'unsure' speakers; and participants who chose the option with que 8 times or less out of 18 were considered as 'no preference' speakers. Please recall that choosing the option with que implied not choosing the option without que since participants had to choose one or the other. None of the participants expressed a preference for both or none. The results are shown in Table 3 below:

Table 3

Preference Task: Individual Results within Group per Preference for the Option with que

\begin{tabular}{lccc}
\hline Group & Preference & Unsure & No preference \\
\hline Heritage Speakers & $10 / 17(59 \%)$ & $0 / 17(0 \%)$ & $7 / 17(41 \%)$ \\
& & & \\
\hline Control & $11 / 15(73 \%)$ & $0 / 15(0 \%)$ & $4 / 15(27 \%)$ \\
\hline
\end{tabular}

As predicted, the control participants showed much higher levels of preference for sentences with the que $(73 \%)$ than the heritage speakers $(59 \%)$. Although there was variation within the monolingual speakers, the vast majority preferred the expected pattern.

In contrast with the previous two tasks, ten heritage speakers preferred the option with que instead of the option without que. It is possible that these heritage speakers may have developed sensitivity to the structures examined. Six out of the ten participants (6/10) were advanced speakers, while the remaining four were intermediate (4/10). It is important to note that three of these four participants were high intermediate (mean range, 37-38/50) and only one was low intermediate (mean, 30/50). The low intermediate speaker, however, reported that she felt equally comfortable in both languages and indicated speaking mostly Spanish at home. Three of the advanced speakers (HSA2, HSB6 and HSB8) and one of the intermediate learners (HSB9) 
also showed a high level of production of DQQ structures in the production task. Only 1/17 participants showed a high level of performance across the three tasks.

\section{Discussion and Conclusions}

The objective of this study was to examine the role of transfer from the majority language in the interpretation and use of double-que questions in Spanish, a linguistic structure so far unexplored. These structures are important to examine for two main reasons. First, this is a syntax-semantics interface-related property, an area of the grammar previously argued to be immune to crosslinguistic influence among adult L2 learners and long-term immigrants (e.g., Sorace, 2005; Tsimpli \& Sorace, 2006). Thus, our objective was to examine if syntax-semantics interface phenomena are also potential loci for incomplete acquisition and optionality among heritage language learners, in contrast with what has been argued for other bilingual populations (L2 learners and L1 attriters). Second, English and Spanish diverge in their syntactic and semantic representation of indirect $w h$-questions. As discussed earlier, Spanish prefers the use of a double-que to form indirect questions with non-ask/wonder verbs of saying in order to avoid semantic ambiguity with statements. In English, the distinction between a statement and an indirect question is marked through verb choice (to ask versus to tell) and a double complementizer is not allowed. This is also a grammatical property not taught in language classrooms. Therefore, we examined whether second generation Spanish speakers were able to overcome transfer effects from English, the majority language, and bilingualism effects.

In contrast with interface vulnerability approaches, which argue that there are no difficulties at the syntax-semantics interface, the results of this study showed lower levels of target use, acceptability and interpretation of DQQ structures among the Spanish heritage speakers, confirming our expectations. The heritage speakers showed significantly lower levels of use of double-que questions than the monolingual speakers in the oral elicitation task. Only $23 \%$ of the heritage speakers showed high levels of double-que production compared to $60 \%$ in the monolingual Spanish control group. The majority of the HL learners did not use double-que structures at all (59\%), which indicates a clear pattern of divergent or incomplete grammar. Even lower results were found in the acceptability judgment task while judging ungrammatical indirect questions without que. In contrast with the monolingual speakers, the HL learners were not sensitive to the difference in meaning imposed by the lack of double-que and accepted both types of sentences (with and without the que) almost equally. 95\% of the HL learners accepted indirect questions introduced by verbs of saying without the required double-que versus $47 \%$ of the monolingual speakers. This clearly indicates a change in the bilingual grammar.

Group and individual results of the preference task also showed overall lower levels of preference for the option with que among the HL learners. However, in contrast with the previous two tasks, 10/17 of the heritage speakers preferred the option with que. This suggests some sensitivity to these structures in the bilingual grammar of these ten speakers. Five out of the ten speakers (5/10) indicated speaking English and Spanish equally at home, and two indicated that they spoke only Spanish. Moreover, 6/10 indicated that they visit Spanish speaking countries, including their parents' country, either frequently or very frequently, and 5/10 felt equally comfortable in both languages. Based on this linguistic profile, it is not surprising that these speakers may have developed some sensitivity to these properties. It appears as if the more 
proficient the speaker is and the more contact she/he has with the minority language, the more sensitive she/he is to DQQ structures. However, this was not the case in the acceptability judgment task or in the production task, where there was no correlation between proficiency level and pattern of L1 use with performance level. Only when the two structures were presented together in the preference task were some of the participants sensitive to the distinction in meaning imposed by the double-que question. These results show that although the properties may have been acquired, there are transfer effects from the English values (single CP structure) which prevent the heritage speakers from having a complete specification of this grammatical structure across the three tasks.

We have argued that the lack of distinction between statements and questions, and convergence towards English might stem from the incomplete acquisition of these structures during childhood and intense contact with the majority language. .5 All but one of HL speakers were born and raised in the US and were exposed to intense contact with English beginning in early childhood. It is important to highlight that incomplete acquisition does not mean that acquisition of the structures in question did not occur. The fact that ten of the heritage speakers showed a certain level of sensitivity in the preference task towards the option with que (grammatical option) indicates that these ten speakers may have knowledge of or partial sensitivity to these structures. This partial knowledge allows the participants to become aware of the difference between the two types of sentences, but only when they are presented together. That is, for the most part, they are choosing between one-phrase (1CP) and two-phrase (2CP) structures as a result of influence from English, and the preference task resolves the ambiguity by presenting both options together. However, transfer from the English single phrase structure interferes with their bilingual representation to the point that they were not able to show target-like knowledge of these structures across all tasks.

The results also show variability in the monolingual norm but to a much lesser extent than in the heritage speaker population. The variability shown by the monolingual speakers is compatible with Suñer's (1991) 2CP analysis. Monolingual speakers accepted the use of que at a high rate. This preference may stem from the fact that the que avoids ambiguity, and most of the control participants demonstrated sensitivity to this across all tasks. Because the control participants only have a $2 \mathrm{CP}$ structure for indirect questions, it is natural that they preferred the unambiguous statement. Moreover, according to Suñer (1991), the lack of double-que with unambiguous verbs (to ask/wonder) does not result in a simplification of the double-que projection. Rather, the $[+\mathrm{WH}]$ que has a null counterpart. We argue that this null counterpart is also present with verbs of saying, leading to some level of variability in the monolingual norm. In the heritage speakers' linguistic norm, this null counterpart is highly activated and over-generalized due to transfer from a single CP structure in English and limited L1 input.

In sum, the overall results show that a complete representation of double-que structures with indirect questions is not in place in the grammar of the HL learners. This syntax-semantics interface property has remained somehow underspecified (not completely developed) in the bilingual grammar of most of the speakers. The group and individual differences between the monolingual Spanish and HL learner groups clearly show a change in the bilingual norm and convergence with English patterns. Partial specification appears to be possible among some of 
the heritage speakers, but transfer from the other language is pervasive, preventing the complete development of these structures even among very proficient bilinguals.

These results contradict interface vulnerability approaches, which claim that there will be neither transfer effects nor acquisition difficulties at the syntax-semantics interface (e.g., Sorace, 2005; Tsimpli \& Sorace, 2006). Although interface approaches do not make specific claims for heritage language development, if syntax-semantics interface structures were spared from transfer effects among adult bilinguals, HL learners should not have shown difficulties with double-que structures. On the other hand, the results confirm previous research in heritage language development (Montrul \& Ionin, in press) and L2 acquisition research (e.g., Bohnacker, 2007; Ivanov, 2009; Rothman, 2008), which document no direct association between acquisition difficulties (or success) and interface-related phenomena.

We conclude that transfer and acquisition difficulties among bilingual speakers, and specifically HL learners, are not limited to one type of interface phenomena (syntax-pragmatics) to the exclusion of others (syntax-semantics). Although some structures are clearly more difficult to acquire and easier to lose, bilingualism effects -including transfer from the majority language, reduced L1 input and use, and attitudinal factors, among others - are a logical consequence of being bilingual in an L2 majority language setting. Finally, it is clear from the results that both the interpretation and use of the Spanish DQQ structures are challenging for HL learners and represent a potential problem for heritage language education. As such, heritage language instructors and educators would benefit from putting special emphasis in the formal teaching of this property, and implementing teaching techniques aimed at mitigating potential transfer effects from the majority language.

\section{Acknowledgement}

We would like to thank two anonymous reviewers from the Heritage Language Journal for their valuable feedback. We would also like to thank Ana T. Pérez-Leroux, Liliana Sánchez, Silvina Montrul and Ronnie Wilbur for their helpful suggestions. All remaining errors are our own.

\section{References}

Au, T., Knightly, L, Jun, S., Oh, J., \& Romo, L. (2008). Salvaging a childhood language. Journal of Memory and Language, 58, 998-1011.

Belletti, A., Bennati, E., \& Sorace, A. (2007). Theoretical and developmental issues in the syntax of subjects: Evidence from near-native Italian. Natural Language and Linguistic Theory, 25(4), 657-689.

Bohnacker, U. (2007). On the "vulnerability" of syntactic domains in Swedish and German. Language Acquisition, 14(1), 31-73.

Chomsky, N., \& Lasnik, H. (1977). Filter and control. Linguistic Inquiry, 8, 425-504.

Cuza, A., (2009). Incomplete acquisition and L1 attrition of subject verb inversion in Spanish: optionality outside the interfaces. Paper presented at the $33^{\text {rd }}$ Linguistic Symposium on Romance Linguistics (LSRL33). University of Arizona. March 2009.

Cuza, A. (2010). The L1 attrition of the Spanish present tense. Hispania, 2, 256-272. 
Coppieters, R. (1987). Competence differences between native and near native speakers. Language, 64, 544-573.

Demonte, V., \& Fernández-Soriano, O. (2009). Force and finiteness in the Spanish complementizer system. Probus, 21, 23-49.

Donaldson, B. (2008). Discourse Competence in Near-Native Speakers of French. Unpublished doctoral dissertation. Indiana University, Bloomington, Indiana.

Eisenchlas, S. (2003). Clitics in child Spanish. First Language, 23, 193-211.

Geeslin, K., \& Guijarro-Fuentes, P. (2006). Second language acquisition of variable structures in Spanish by Portuguese speakers. Language Learning, 56(1), 53-107.

Hawkins, R., \& Chan, Y. (1997). The partial availability of UG in SLA: The 'failed functional features hypothesis'. Second Language Research, 13, 187-226.

Ivanov, I. (2009). Topicality and clitic doubling in L2 Bulgarian: A test case for the interface hypothesis. In M. Bowles, T. Ionin, S. Montrul \& A. Tremblay (Eds.), Proceedings of the 10th Generative Approaches to Second Language Acquisition Conference (GASLA) (pp. 1724). Somerville, MA: Cascadilla Proceedings Project.

Jarvis, S., \& Pavlenko, A. (2008). Crosslinguistic influence in language and cognition. London: Routledge.

Lambert, B. (2008). Family language transmission: actors, issues, outcomes. Frankfurt: Peter Lang.

Lapidus, N., \& Otheguy, R. (2005). Overt nonspecific ellos in the Spanish of New York. Spanish in Context, 2, 157-176.

Liceras, J. (1989). On some properties of the "pro-drop" parameter: Looking for missing subjects in non-native Spanish. In S.M. Gass \& J. Schachter (Eds.), Linguistic perspectives on second language acquisition (pp. 109-133). Cambridge: Cambridge University press.

Loebell, H., \& Bock, K. (2003). Structural priming across languages. Linguistics, 41, 791-824.

Montrul, S. (1998). The L2 acquisition of dative experiencer subjects. Second Language Research, 14, 27-61.

Montrul, S. (2002). Incomplete acquisition and attrition of Spanish tense/aspect distinctions in adult bilinguals. Bilingualism: Language and Cognition, 5, 39-68.

Montrul, S. (2004). Subject and object expression in Spanish heritage speakers: A case of morphosyntactic convergence. Bilingualism: Language and Cognition, 7(2), 125-142.

Montrul, S. (2009). Incomplete acquisition of tense-aspect and mood in Spanish heritage speakers: Special issue of The International Journal of Bilingualism, 13(2), 1-31.

Montrul, S., \& Bowles, M. (2010). Is grammar instruction beneficial for heritage language learners? Dative case marking in Spanish. The Heritage Language Journal, 7(1), 47-63.

Montrul, S., Foote, T., \& Perpiñán, S. (2008). Knowledge of Wh-movement in Spanish L2 learners and heritage speakers. In J. B. de Garavito \& E. Valenzuela (Eds.), Proceedings of the $10^{\text {th }}$ Hispanics Linguistics Symposium. Somerville, MA: Cascadilla Proceedings Project.

Montrul, S., \& Ionin, T. (2010). Transfer effects in the interpretation of definite articles by Spanish heritage speakers. Bilingualism: Language and Cognition 13, 4, 449-473.

Montrul, S., \& Perpiñán, S. (this issue). Assessing differences and similarities between Instructed Heritage Language Learners and L2 learners in their knowledge of Spanish Tense Aspect and Mood (TAM) Morphology. Heritage Language Journal, 8(1). 
Montrul, S., \& Rodriguez Louro, C. (2006). Beyond the syntax of the null subject parameter. In V. Torrens \& L. Escobar (Eds.), The acquisition of syntax in Romance languages (pp. 401418). Amsterdam: John Benjamins.

Montrul, S., \& Slabakova, R. (2003). Competence similarities between native and near-native speakers: An investigation of the Preterite/Imperfect contrast in Spanish. Studies in Second Language Acquisition, 25(3), 351-398.

Müller, N., \& Hulk, A. (2001). Crosslinguistic influence in bilingual language acquisition: Italian and French as recipient languages. Bilingualism: Language and Cognition, 4, 1-21.

Pérez-Leroux, A.T., Cuza, A., \& Thomas, D. (in press). From parental attitudes to input conditions: A look at Spanish-English bilingual development in Toronto. In K. Potowski \& J. Rothman (Eds.), Bilingual youth: Spanish in English-speaking societies. John Benjamins.

Plann, S. (1982). Indirect Questions in Spanish. Linguistic Inquiry, 13(2), 297-312.

Polinsky, M. (2008). Gender under incomplete acquisition: Heritage speakers' knowledge of noun categorization. Heritage Language Journal, 6(1), 40-71.

Potowski, K. (2004). Student Spanish use and investment in a dual immersion classroom: Implications for second language acquisition and heritage language maintenance. Modern Language Journal, 88(1), 75-101.

Potowski, K, Jegerski, J., \& Morgan-Short, K. (2009). The effects of instruction on linguistic development in Spanish heritage language speakers. Language Learning, 59(3), 537-579.

Rivero, M. (1980). On left-dislocation and topicalization in Spanish. Linguistic Inquiry, 11, 363395.

Rothman, J. (2007). Heritage speaker competence differences, language change and input type: Inflected infinitives in heritage Brazilian Portuguese. International Journal of Bilingualism, 11(4), 359-389.

Rothman, J. (2008). Pragmatic deficits with syntactic consequences: L2 pronominal subjects and the syntax-pragmatics interface. Journal of Pragmatics, 41, 951-973.

Rothman, J. (2009) Understanding the nature and outcomes of early bilingualism: Romance languages as heritage languages. International Journal of Bilingualism, 13(2), 145-155.

Schmid, M., Köpke, B., Keijzer, M., \& Weilemar, L. (2004). First Language Attrition: Interdisciplinary Perspectives on Methodological Issues. Amsterdam/Philadelphia: John Benjamins.

Schwartz, B., \& Sprouse, R. (1996). L2 cognitive states and the full transfer/full access model. Second Language Research, 12, 40-72.

Serratrice, L., Sorace, A., \& Paoli, S. (2004). Subjects and objects in Italian-English bilingual and monolingual acquisition. Bilingualism: Language and Cognition, 7, 183-206.

Silva-Corvalán, C. (2003). Linguistic consequences of reduced input in bilingual first language acquisition. In S. Montrul \& F. Ordóñez (Eds.), Linguistic theory and language development in Hispanic languages (pp. 375-397). Somerville, MA: Cascadilla Press.

Silva-Corvalán, C. (1994). Language contact and change. Oxford: Oxford University Press.

Sorace, A. (2000). Differential effects of attrition in the L1 syntax of near-native L2 speakers. In C. Howell, S. Fish \& T. Keith-Lucas (Eds.), Proceedings of the 24th Boston University Conference on Language Development (pp. 719-725). Somerville, MA: Cascadilla Press.

Sorace, A. (2005). Selective optionality in language development. In L. Cornips \& K. Corrigan (Eds.), Syntax and variation: Reconciling the biological and the social (pp. 46-111). Amsterdam: John Benjamins. 
Sorace, A. (2004). Native language attrition and developmental instability at the syntaxdiscourse interface: Data, interpretations and methods. Bilingualism: Language and Cognition, 7, 143-145.

Sorace, A., \& Filiaci, F. (2006). Anaphora resolution in near-native speakers of Italian. Second Language Research, 22(3), 339-368.

Suñer, M. (1991). Indirect questions and the structure of CP: Some consequences. In H. Campos \& F. Martínez-Gil (Eds.), Current Studies in Spanish Linguistics (pp. 283-312). Washington D.C.: Georgetown University Press.

Suñer, M. (1993). About indirect questions and semi-questions. Linguistics and Philosophy, $16(1), 45-77$.

Tsimpli, I.M., \& Roussou, A. (1991) Parameter-resetting in L2? UCL Working Papers in Linguistics, 3, 149-70.

Tsimpli, I.M. \& Sorace, A. (2006). Differentiating interfaces: L2 performance in syntaxsemantics and syntax-discourse phenomena. In D. Bamman, T. Magnitskaia, \& C. Zaller (Eds.), Proceedings of the $30^{\text {th }}$ Annual Boston University Conference on Language Development, 30 (2), 653-664. Somerville, MA: Cascadilla Press.

Tsimpli, I.M., Sorace, A., Heycock, C., \& Filiaci, F. (2004). First language attrition and syntactic subjects: A study of Greek and Italian near-native speakers of English. International Journal of Bilingualism, 8, 257-277.

White, L. (1987). Against comprehensible input: The input hypothesis and the development of L2 competence. Applied Linguistics, 8(1), 95-110.

White, L., \& Genesee, F. (1996). How native is near native? The issue of ultimate attainment in adult second language acquisition. Second Language Research, 12, 233-265.

Zobl, H. (1980). The formal and developmental selectivity of L1 influence on L2 acquisition. Language Learning, 30(1), 43-57.

\section{Notes}

1. Rothman (2007) argues that the differences exhibited by heritage speakers do not necessarily stem from incomplete acquisition during childhood. Instead, he argues that they might stem from the complete acquisition of the non-standard contact variety to which they have been exposed and the limited exposure to formal schooling.

2. In some varieties of Spanish (e.g., Argentinean Spanish), the use of the double-que in embedded questions is not very common. This is particularly so with what-embedded questions (\#Juan me dijo que qué compré "John asked me what I bought").

3. This filter prevents a complementizer phrase from containing both a wh-word and a complementizer.

4. The monolingual participant from Colombia showed $100 \%$ target use. 
5. It could also be argued that these results stem from L1 attrition in the absence of longitudinal data. However, we consider L1 attrition as the erosion of previously acquired properties among adult immigrants who immigrated to the L2 context with a fully developed L1 grammar (e.g., Sorace, 2004). Therefore, we do not consider the possibility of L1 attrition in this case. 